\title{
Web 2.0 e Formação de Professoras/es de Línguas Estrangeiras/Adicionais: foco em um grupo de estudos virtual
}

Web 2.0 and Foreign/Additional Language Teacher Education: FOCUS IN A VIRTUAL STUDY GROUP

\section{Viviane Pires Viana Silvestre* Rosane Rocha Pessoa**}

Resumo: No cenário contemporâneo, torna-se cada vez mais urgente refletir sobre como os recursos disponibilizados pelas novas tecnologias de informação e comunicação podem servir à educação e, mais especificamente, à formação de professoras/es. Este estudo, de base qualitativo-interpretativista (DENZIN; LINCOLN, 2006), reflete sobre possíveis contribuições e limitações do recurso disponibilizado pela Web 2.0 "grupo de estudos virtual", desenvolvido a partir do grupo de discussão Google Groups, para a formação de professoras/es de línguas estrangeiras/adicionais. Para tanto, temos como foco de análise alguns dados das interações virtuais do grupo de estudos "Transição - Formação de professoras/es de língua estrangeira" e as considerações de algumas/uns de suas/seus participantes, geradas por meio de um questionário semiaberto, acerca desse recurso virtual de formação docente. A análise aponta a relevância desse recurso potencializado pela Web 2.0 para a formação continuada docente e nos incita a buscar maneiras de otimizá-lo, problematizando suas limitações e, ao mesmo tempo, de

\footnotetext{
* Mestre em Letras e Linguística pela Universidade Federal de Goiás (2008). Doutoranda no mesmo Programa de Pós-Graduação. Docente efetiva da Universidade Estadual de Goiás - Câmpus Inhumas. Contato: vivianepvs@gmail.com.

** Doutora em Estudos Linguísticos pela Universidade Federal de Minas Gerais (2002). Professora Associada 3, Universidade Federal de Goiás. Contato: pessoarosane@gmail.com.
} 
torná-lo mais acessível a outras/os professoras/es de línguas estrangeiras/ adicionais ${ }^{1}$.

Palavras-chave: Grupo de estudos virtual. Web 2.0. Formação de professoras/es de línguas estrangeiras/adicionais.

\begin{abstract}
Nowadays, it is imperative to reflect on how the resources provided by new information and communication technologies may serve to education and, more specifically, to teacher education. This study focuses on possible contributions and limitations of the resource provided by Web 2.0 "virtual study group", developed from the discussion group Google Groups, to foreign/additional language teacher education. To that end, we analyse some data from the virtual interactions of the study group "Transição - Formação de professoras/es de lingua estrangeira" and some of its participants' considerations about this virtual teacher education resource, generated by a semi-open questionnaire. The analysis highlights the relevance of this resource provided by Web 2.0 to in service teacher education and incites us to seek ways to optimize it, problematizing its limitations, while making it more accessible to other foreign/additional language teachers.
\end{abstract}

Keywords: Virtual study group. Web 2.0. Foreign/Additional language teacher education.

\title{
Introdução
}

Estudiosas/os de diferentes áreas do conhecimento têm discutido sobre a influência dos recursos ligados às novas tecnologias de informação e comunicação (doravante NTICs) em seus contextos de atuação profissional.

${ }^{1}$ Neste estudo, utilizamos também o termo linguas adicionais - e não apenas linguas estrangeiras - seguindo uma tendência crítica da área de Linguística Aplicada, que concebe a língua não como algo estranho à/ao aprendiz, mas sim como um recurso utilizado por ela/e para se construir socialmente e intervir no mundo que a/o cerca (NICOLAIDES; TILIO, 2013). 
A área de Linguística Aplicada também tem debatido sobre o assunto, especialmente ao tratar de contextos de educação linguística. Nessa direção, há alguns estudos (BOHN, 2010; MARZARI; LEFFA, 2013) que se voltam para a relação entre os recursos disponibilizados pelas NTICs, em especial os da chamada Web 2.0, e a formação de professoras/es de língua estrangeira/ adicional (doravante LE/LA).

Nesse sentido, a proposta deste estudo é refletir acerca das possíveis contribuições e/ou limitações do recurso "grupo de estudos virtual", desenvolvido a partir do grupo de discussão Google Groups, para a formação de professoras/es de LE/LA. Para tanto, temos como foco de análise alguns dados das interações virtuais do grupo de estudos "Transição - Formação de professoras/es de língua estrangeira" e as considerações de algumas/uns de suas/seus participantes, geradas por meio de um questionário semiaberto, acerca desse recurso virtual de formação docente. Apesar de parte da análise conter dados quantitativos, o aparato metodológico que sustenta este trabalho é o paradigma qualitativo-interpretativista (DENZIN; LINCOLN, 2006).

Antes de seguir com a descrição mais detalhada do grupo de estudos virtual Transição, trazemos um breve apanhado teórico que respalda esta proposta de trabalho.

\section{NTICs, Web 2.0 e Formação Docente: algumas intersecções}

Mesmo diante de um cenário nacional de desigualdade de acesso às redes digitais, em que mais de $53 \%$ da população brasileira ainda não usa a internet (SALLOWICZ, 2013), não há como negar a influência das mídias digitais nos diferentes domínios da vida contemporânea. Todavia, segundo Mota e Scott (2014), o mundo educacional está atrasado na absorção de ferramentas e dos benefícios das tecnologias digitais, que foram adotadas décadas atrás no âmbito das finanças, da indústria e da medicina. Nesse sentido, torna-se urgente refletir sobre como os recursos disponibilizados pelas NTICs podem servir à educação e, mais especificamente, à formação de professoras/es, tanto universitária como continuada.

Mota e Scott (2014) falam de três revoluções educacionais ao longo da nossa história, que tiveram como elementos motores as tecnologias educacionais: a primeira delas foi decorrente da criação da escola nos séculos 
V-VI a.C., na Grécia Antiga; a segunda foi impulsionada pela invenção do livro no século XV, na Europa; e a terceira, pela incorporação das tecnologias digitais na educação, desenvolvidas no século XXI. Para os autores, as

Tecnologias digitais são sustentadas pela introdução de uma nova mídia, a World Wide $W e b$, e por um modelo original de representação, via hipertextos, os quais, em conjunto, resultam na reconfiguração dos arranjos discursivos, bem como do lugar ocupado pelo[a] leitor[a], portanto, do[a] educando[a]. (MOTA; SCOTT, 2014, p. 45)

De fato, essa rede mundial tem criado a possibilidade de relações mais democráticas no que diz respeito à construção do texto, pois pode promover conversações complexas, já que as funções de autoras/es e de leitoras/es se tornaram mais fortemente imbricadas uma na outra (LANDOW, 1992 citado por MOTA; SCOTT, 2014). Nessa mesma linha de pensamento, Oliveira (2013, p. 204) afirma que, "na presente era de desenvolvimento tecnológico, novos espaços para obtenção de informações e de construção de conhecimento foram abertos". De fato, considerando a nova era da internet, conhecida como Web 2.0, vários recursos virtuais de construção colaborativa de conhecimentos se tornaram possíveis.

Embora haja controvérsias quanto ao termo Web 2.0 (BOHN, 2010; OLIVEIRA, 2013), reconhece-se como principal característica dessa nova geração da internet a mudança de papel da/o usuária/o - de consumidora/r para colaboradora/r do conteúdo da rede. Nas palavras de Bohn (2010, p. 25), "Colaborar é o principal verbo conjugado na era da Web 2.0. Por meio da colaboração, os[as] internautas constroem uma ampla rede de conhecimento no mundo virtual, compartilhando ideias e conhecimento".

De acordo com Andrelo e Nakashima (2012), especialistas da área de tecnologia e informação consideram a Web 2.0 como uma atitude e não como uma tecnologia, uma vez que se pauta no incentivo à participação cada vez mais ativa das/os usuárias/os da rede. Segundo as autoras, "com o surgimento da Web 2.0, está ocorrendo uma convergência de mídias e de participação mais ativa dos cidadãos, pois um dos seus princípios baseia-se 
na 'inteligência coletiva' (LÉVY, 1998) ${ }^{[2]}$, ou seja, na produção e compartilhamento de conteúdos entre os usuários" (ANDRELO; NAKASHIMA, 2012, p. 127). No entanto, Freitas (2012, p. 7) argumenta:

Incorporar as ferramentas da Web $2.0 \mathrm{em}$ processos formativos não é uma tarefa fácil, pois implica incorporar novas formas de intervenção, e nem sempre os[as] professores[as] estão preparados[as] ou querem fazer mudanças em suas práticas pedagógicas. Implica reconhecer novos cenários e exige que o[a] professor[a] saiba reconhecer o uso de ferramentas e recursos tendo como foco a aprendizagem. Estes desafios perpassam desde a formação inicial e continuada dos[as] professores[as] em TIC até a aceitação do[a] aluno[a] em utilizar espaços e ferramentas que ele[ela] já os (sic) utiliza, mas atribuindo a eles fins educativos.

Freitas (2012), então, enumera uma série de ferramentas disponíveis na rede que tem potencial de ser usadas com propósitos educacionais e formativos, tais como: correio eletrônico (e-mail), mensagem instantânea, fórum, grupo de discussão, chat, blog, Wiki etc. Para este estudo, interessa a ferramenta do tipo "grupo de discussão".

O recurso "grupo de discussão", disponibilizado a partir da Web 2.0, refere-se a um grupo de internautas com interesses em comum que se comunicam entre si por meio de um mesmo endereço eletrônico ou página virtual (webpage) do grupo. As mensagens do grupo podem ser lidas e postadas pelo e-mail pessoal de cada participante e/ou na própria página do grupo, como em um fórum. Esses grupos podem ser criados para acesso público ou restrito a seus membros. Em 2001, a empresa americana de serviços on-line e software Google passou a oferecer esse recurso, conhecido como Google Groups (Grupos do Google).

Esse recurso da Web 2.0 permite, por exemplo, a comunicação assíncrona entre profissionais que comungam de interesses em comum, entre elas/es, professoras/es de LE/LA. Nos estudos sobre NTICs e formação

${ }^{2}$ LÉVY, P. A inteligência coletiva: por uma antropologia do ciberespaço. São Paulo: Loyola, 1998. 
de professoras/es de LE/LA faltam trabalhos que se voltem para estudar em que medida essa ferramenta pode trazer contribuições para o desenvolvimento profissional dessas/es docentes. Espera-se que este estudo traga subsídios nessa direção.

\section{Perfil do Grupo Transição}

Em agosto de 2012, formou-se o GT Transição ${ }^{3}$ - Grupo de estudos sobre formação de professoras/es de língua estrangeira - da Faculdade de Letras de uma universidade federal, coordenado por nós. O principal anseio do grupo é problematizar a formação de professoras/es de LE/LA, de modo a promover o desenvolvimento profissional das/os envolvidas/os e um ensino mais eficaz de LE/LA nas escolas regulares e no ensino superior. O GT foi formado a partir dos trabalhos de um grupo de pesquisa do Diretório dos Grupos de Pesquisa no Brasil, cadastrado no CNPQ, que conta com três linhas de pesquisa distintas: competências e novas tecnologias na formação de professoras/es; formação crítica e/ou colaborativa de professoras/es de língua estrangeira; língua(gem) e subjetividade. O grupo Transição propõe discussões acerca de diferentes temáticas relacionadas às três linhas de pesquisa e promove encontros presenciais mensais e também virtuais, por meio do recurso da Web 2.0 "Grupos do Google"4.

Em janeiro de 2014, o grupo contava com 28 integrantes de diferentes localidades (Goiás - participação majoritária -, São Paulo, Mato Grosso, Tocantins, Distrito Federal, Pará e Minas Gerais) e contextos educacionais diversos, como alunas/os, ex-alunas/os e/ou professoras/es das seguintes instituições: Universidade Federal de Goiás (UFG), Universidade Estadual de Goiás (UEG), Universidade Federal do Mato Grosso (UFMT), Universidade Federal do Pará (UFPA), Instituto Federal Goiano (IFG), Instituto Federal de Brasília (IFB), Instituto Federal do Triângulo Mineiro (IFTM), Universidade Estadual de Campinas (UNICAMP), escolas da rede

\footnotetext{
3 A escolha do nome do grupo foi inspirada em um vídeo compartilhado logo no início da criação do grupo virtual, que se encontra disponível em: <http:/ /bit.do/bFJKj>. Acesso em: 24 jan. 2014.

${ }^{4}$ Endereço eletrônico do grupo: fple@googlegroups.com.
} 
pública e privada e centros de idiomas. A participação de pessoas de lugares tão diversos só é possível pelo uso do recurso virtual, uma vez que grande parte das/os integrantes participa apenas virtualmente do grupo. Dentre elas/es, dez participam desde o primeiro mês, oito entraram ainda no primeiro semestre de criação do grupo, seis entraram no segundo semestre e quatro integraram o grupo no terceiro semestre. Desde o início, apenas dois membros pediram o cancelamento de suas inscrições no grupo.

Para fazer parte do grupo Transição é preciso receber e aceitar o convite enviado pela proprietária do grupo (participante responsável pela criação do grupo virtual). Dessa forma, somente membros do grupo podem postar mensagens (enviadas automaticamente para o e-mail cadastrado de cada participante) e visualizar o conteúdo postado.

Neste estudo, tomamos como foco de análise apenas a versão virtual do grupo de estudos Transição, considerando seus primeiros 18 meses, a fim de refletir sobre o papel desse recurso da Web 2.0 na formação e prática docente de seus membros.

\section{Grupo Transição: uma fotografia das interações virtuais}

No período de agosto de 2012 a janeiro de 2014 foram registrados, na página do grupo, 395 tópicos de mensagens. Desses tópicos, 63 foram gerados de agosto de 2012 a janeiro de 2013, 169 de fevereiro a julho de 2013 e 156 de agosto de 2013 a janeiro de 2014, como ilustra o Gráfico 1.

Os dados do Gráfico 1 indicam que houve um crescimento substancial no número de tópicos de mensagens enviadas pelo grupo no segundo semestre de sua criação (aumento de 168\%) e uma pequena queda desse número (queda de $7,7 \%$ ) no terceiro semestre. 


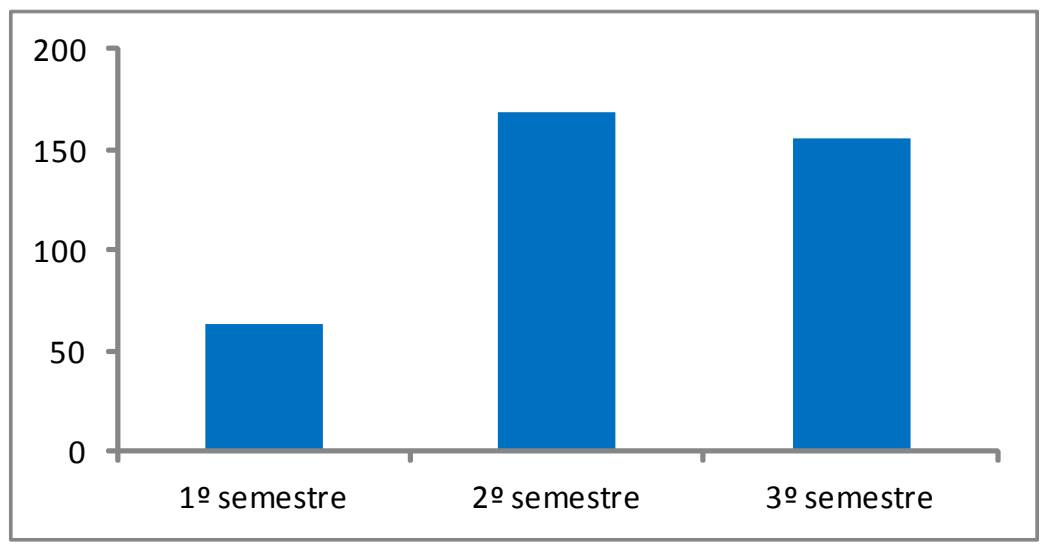

Gráfico 1-Quantidade de tópicos de mensagens registradas a cada semestre

O levantamento do conteúdo dos tópicos dessas mensagens aponta para dez categorias, listadas a seguir, com o número de recorrência e porcentagem em relação ao número total de tópicos. Ressalte-se que foi analisado apenas o conteúdo das mensagens de iniciação, não sendo consideradas as postagens que emergiram a partir desses tópicos iniciais.

1) Divulgacão de eventos e oportunidades - 152 mensagens $(38,48 \%)$;

2) Compartilhamento de textos - 53 mensagens (13,41\%);

3) Compartilhamento de vídeos - 51 mensagens (12,91\%);

4) Organização dos encontros presenciais - 41 mensagens (10,38\%);

5) Compartilhamento de noticias - 40 mensagens $(10,12 \%)$;

6) Administração/gerenciamento-14 mensagens (3,55\%);

7) Pedido de ajuda - 10 mensagens (2,53\%);

8) Congratulações - 9 mensagens $(2,28 \%)$;

9) Sugestão de atividades para aulas - 4 mensagens $(1,01 \%)$;

10) Outros/diversos - 21 mensagens (5,33\%);

O Gráfico 2, a seguir, elucida mais claramente esses números: 


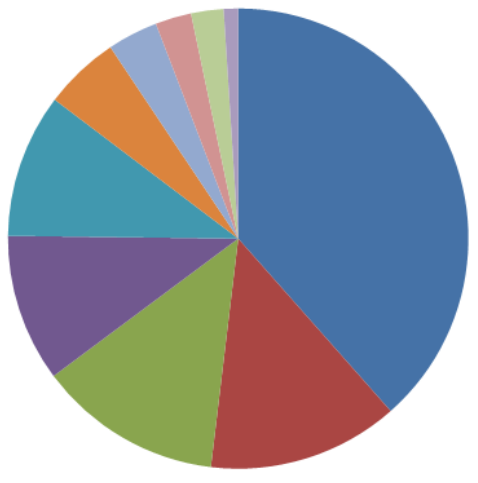

- Divulgação de eventos e oportunidades (38,48\%)

- Compartilhamento de textos $(13,41 \%)$

- Compartilhamento de vídeos (12,91\%)

• Organização dos encontros presenciais (10,38\%)

- Compartilhamento de notícias (10,12\%)

- Outros/diversos (5,33\%)

* Administração/gerenciamento (3,55\%)

Pedido de ajuda (2,53\%)

- Congratulações $(2,28 \%)$

E Sugestão de atividades para aulas (1,01\%)

Gráfico 2 - Categorização do conteúdo das mensagens de iniciação

Nota-se, então, que grande parte das mensagens de iniciação enviadas pelo grupo tem como foco a divulgação de chamadas para publicações em revistas e periódicos científicos, divulgação de eventos da área, concursos e demais oportunidades profissionais. $\mathrm{O}$ mesmo dado foi constatado nos estudos de Perin (2009) e Calvo e Freitas (2011), ambos focalizando a análise das mensagens do grupo virtual ENFOPLI (Comunidade de Prática de Formadores de Professores de Língua Inglesa do Paraná), no período de 2003-2007 e 2010-2011, respectivamente. Assim como apontado nesses dois estudos, as mensagens dessa primeira categoria são as que menos fomentam discussão e demais postagens no grupo.

Em contrapartida, percebe-se um número bastante representativo de compartilhamentos de textos, vídeos e notícias que, somados, equivalem a $39,73 \%$ das mensagens de iniciação, superando a primeira categoria. Esse dado sugere que o grupo virtual tem servido como ferramenta de colaboração e troca de materiais e informações de interesse comum. A fim de esclarecer o conteúdo desses materiais compartilhados (textos, vídeos e notícias), essas três categorias foram subdivididas de acordo com suas temáticas principais: educação (ensino e aprendizagem em geral), ensino de LE/LA (em especial, 
as línguas inglesa e espanhola), temas críticos $^{5}$ (especialmente, raça/racismo e gênero/sexualidade) e outros, como ilustrado no Gráfico 3, a seguir:

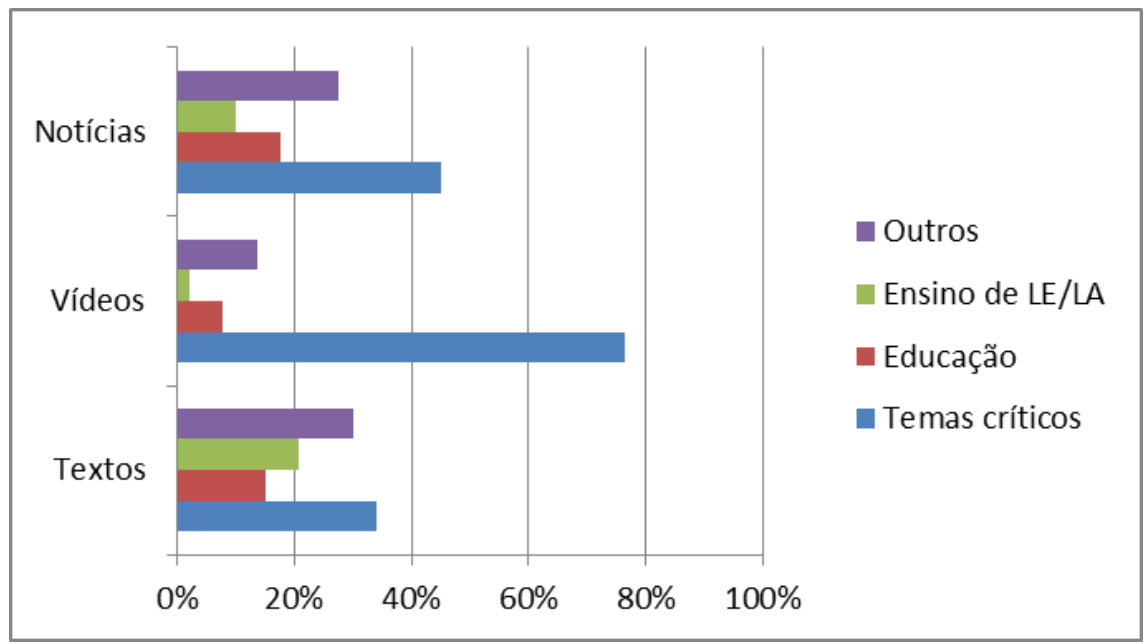

Gráfico 3 - Subcategorização dos materiais compartilhados

Percebe-se, no Gráfico 3, que a maioria dos vídeos e notícias compartilhadas no grupo focaliza temáticas críticas. Esse dado revela a predominância de uma das três linhas de pesquisa que, a priori, fomentariam as discussões do grupo, qual seja: "formação crítica e/ou colaborativa de professores/as de língua estrangeira". Como registrado na página do grupo cadastrado no CNPq, essa linha de pesquisa reúne estudos que têm como objetivo "problematizar, por meio da reflexão colaborativa entre professoras/es de diferentes contextos, temas como identidade, classe, raça, gênero e interculturalidade, contribuindo, assim, para uma formação mais crítica dessas/es professoras/es". Apesar de a maioria dos textos, vídeos e notícias com foco em temas críticos não estar diretamente ligada ao ensino

${ }^{5}$ Temas de cunho político-social (classe, raça, etnia, gênero, sexualidade etc.), que focalizam noções de poder, desigualdade, discriminação, resistência e luta (URZÊDA-FREITAS, 2012; PESSOA, 2014). 
de LE/LA, grande parte desse material contribui para uma formação mais crítica das/os participantes e, por vezes, se transforma em recursos utilizados pelas/os professoras/es em suas aulas, como será evidenciado na seção seguinte. Por outro lado, o mesmo gráfico sinaliza a baixa recorrência de compartilhamento de textos, vídeos e notícias diretamente relacionados à educação, em geral, e ao ensino de LE/LA, em específico.

A categorização dos conteúdos das mensagens de iniciação, ilustrada no Gráfico 2, aponta outro papel importante do grupo virtual: organização dos encontros presenciais. Por meio desse recurso virtual, o grupo decide e compartilha o material a ser estudado e define a agenda dos encontros presenciais. Ressalte-se que, sem esse recurso, a participação colaborativa nessas decisões se inviabilizaria.

As demais categorias que emergiram da análise compõem um número reduzido de mensagens, sendo enviadas esporadicamente pelo grupo. Essas categorias englobam mensagens de congratulações (aprovação em processos seletivos, defesas de TCCs, dissertações e teses, felicitações em geral), que demonstram e fortalecem os laços afetivos existentes no grupo; pedidos de ajuda (em geral, relacionados à prática pedagógica das/os participantes) e sugestão de atividades prontas para aulas de LE/LA, que dão indícios do sentimento de confiabilidade criado no grupo; questões administrativas, geralmente relacionadas à inclusão de novos membros; e, por fim, questões diversas das comumente compartilhadas pelo grupo.

Como já ressaltado, a análise aqui brevemente apresentada se pautou nos tópicos das mensagens de iniciação, que totalizaram 395 no período em foco. A partir desses tópicos, foram geradas 1.218 postagens diversas, que, por fugirem do escopo deste texto, não serão analisadas. No entanto, convém esclarecer que, apesar de esses números indicarem uma média de 3,09 postagens para cada tópico iniciado, o que ocorre, de fato, é que há um grande número de tópicos que não geram postagens pelas/os demais participantes do grupo, especialmente as mensagens da primeira categoria. Por outro lado, as mensagens das demais categorias tendem a render um número mais elevado de postagens, isto é, provocam discussão no grupo.

Outro dado importante de ser salientado diz respeito ao número de participantes efetivamente ativas/os no grupo, isto é, aquelas/es que frequentemente postam mensagens. Pouco mais de um terço das mensagens postadas no grupo foram feitas por uma mesma participante (440). Somadas 
as mensagens postadas por outras duas participantes (188 e 181), têm-se quase o segundo terço, restando pouco mais do outro terço das postagens para as/os demais participantes (grande parte raramente posta mensagens no grupo). Esse dado parece, de certo modo, corroborar a medida 90-9-1 proposta por Nielsen (2006) para avaliar a participação de membros de comunidades virtuais. O número noventa (90) equivale ao percentual das/os chamadas/os lurkers, ou seja, participantes que leem e acompanham as discussões, mas raramente participam de forma ativa; o número nove (9) diz respeito à porcentagem de participantes que contribuem de tempos em tempos; e, por fim, o número um (1) refere-se ao percentual de participantes que mais postam mensagens. Apesar de reconhecer que o ideal seria amenizar essa medida, talvez numa proporção menos desigual de 80-16-4, Nielsen (2006) argumenta que é preciso entender que essa desigualdade na quantidade de participação sempre existirá em comunidades virtuais. Calvo et al. (2013, p. 315) justificam que "a sensação de não urgência, a não familiarização com as tecnologias e o medo de possível exposição, por exemplo, são alguns dos fatores que podem prejudicar significativamente o percentual de participação em comunidades virtuais". Outro fator fundamental nessa lista é a falta de tempo, já que essa é moeda corrente no mundo atual. Na sequência, discutimos as considerações de algumas/uns participantes a esse respeito e sobre demais fatores relacionados ao grupo Transição e à formação/prática docente.

\section{Grupo Transição e Formação/Prática Docente: olhares de dentro}

Com vistas a conhecer como as/os participantes do Transição têm percebido a relação entre a participação no grupo de estudos virtual e sua formação/prática docente, elaboramos um questionário composto por seis questões $^{6}$ e enviamos a solicitação de resposta ao grupo. Para manter o

${ }^{6}$ Questões do questionário: 1) Por que você aceitou o convite para participar do Grupo do Google "Transição - Formação de Professoras/es de Língua Estrangeira"?; 2) A participação no grupo tem contribuído para sua prática pedagógica? Justifique/ exemplifique.; 3) A participação no grupo tem contribuído para sua formação profissional? Justifique/exemplifique.; 4) Como você avalia sua participação no grupo? Por quê?; 5) O que poderia ser diferente no grupo?; 6) Quais as vantagens e/ou desvantagens de participar de um grupo de estudos virtual?. 
anonimato das respostas, organizamos e enviamos o formulário usando um recurso do Google Docs. No entanto, a tentativa não foi bem sucedida. Algumas/uns participantes disseram, informalmente, que haviam respondido ao formulário, mas que não conseguiram enviá-lo. Por esse motivo, tivemos de abrir mão da possibilidade de anonimato das respostas e solicitamos novamente as respostas ao questionário, desta vez, usando o e-mail particular de cada uma/um. Das/os 28 participantes, 10 devolveram o questionário respondido (o equivalente a pouco mais de um terço). Apesar de ser um número bem inferior ao que esperávamos, cremos que não inviabiliza a proposta deste estudo.

Com exceção de um participante, todas/os as/os que responderam ao questionário atuam, direta ou indiretamente, com o ensino de LE/LA: três em contexto universitário, quatro na Educação Básica e dois em centros de idiomas. Além disso, cinco participam do grupo Transição desde o início de sua criação, dois há quase um ano e três há menos de seis meses. A fim de resguardar suas identidades, cada participante será identificado pela inicial $\mathrm{P}$ seguido de um número de 1 a 10.

A análise das respostas ao questionário evidenciou cinco tópicos principais relacionados ao grupo de estudos virtual: motivação inicial para fazer parte do grupo virtual, contribuições para a formação docente, contribuições para a prática pedagógica, autoavaliação sobre a participação no grupo, vantagens e desvantagens de participar de um grupo de estudos virtual. Passamos, agora, a discutir cada um deles separadamente.

\section{Motivação inicial para fazer parte do grupo virtual}

As/Os participantes são unânimes em acreditar no potencial de colaboração e coconstrução de conhecimentos via grupo de estudos virtual, principal razão que as/os motivou a se integrar ao grupo Transição. Além disso, P3 reconhece que seu trabalho é demasiado solitário, realidade da maioria das/os docentes (TARDIF; LESSARD, 2008), e vê, no grupo virtual, uma oportunidade de compartilhar e discutir sobre questões que são de seu interesse profissional. Segue um excerto da consideração de P3: 
... tenho um trabalho muito solitário ${ }^{7}$ e gostaria de poder discutir assuntos controversos que circulam o mundo dos alunos. (P3)

Por sua vez, P5 e P6 viram, no grupo Transição, a possibilidade de refletir sobre as perspectivas críticas de ensino de línguas, já confirmando a ênfase dada no grupo para essa linha de estudos, como apontado na seção anterior. Seguem os trechos das considerações de P5 e P6 a esse respeito:

... vi no grupo a possibilidade de me aproximar mais das leituras e das discussões sobre o ensino crítico. (P5)

Para [...] ter mais contatos com colegas e amigos que possam indireta e diretamente compartilhar suas experiências e estudos, bem como suas dúvidas, acerca do mundo atual e da teoria crítica. (P6)

Outro fator que motivou P9 a participar do grupo virtual foi sua impossibilidade de participar dos encontros presenciais:

Além disso, como não poderia participar dos encontros presenciais, achei que poderia fazê-lo através do Grupo do Google. (P9)

Nota-se, então, que muitas das motivações iniciais das/os participantes em se integrarem ao Transição se relacionam ao desejo de formação profissional contínua e viram nesse recurso virtual uma possibilidade de concretização desse anseio.

\section{Contribuições para a formação docente}

As respostas das/os professoras/es dão indícios de que a participação no grupo de estudos virtual Transição tem trazido contribuições para sua formação docente. Segundo algumas/uns participantes, as colocações das/os colegas, a diversidade entre os membros do grupo e o material

\footnotetext{
7 Todas as ênfases em negrito nos excertos foram adicionadas por nós.
} 
compartilhado provocam reflexões acerca do próprio fazer docente, bem como trazem inquietações pessoais, principalmente devido às temáticas críticas que prevalecem nas discussões do grupo. Seguem alguns excertos a esse respeito:

... é uma fonte de materiais, textos e discussões que me ajudam a pensar a formação docente. (P1)

Tem servido como fórum de crescimento profissional, pois permite contato com professores de diferentes formações, origens, contextos, cidades etc. (P2)

Aprendo muito sobre a perspectiva crítica e o ensinoaprendizagem de línguas como prática social nas discussões que ocorrem por aqui [...]. (P4)

[...] creio que por meio das discussões que leio, das trocas entre os/as colegas, consigo me firmar como uma pessoa que precisa pensar a respeito do que está exposto ali [...]. Me reconheço preconceituosa muitas vezes e isso me leva a refletir mais sobre os acontecimentos e as pessoas ao meu redor. (P5)

[...] ao ler as reflexões das/os participantes sobre os diversos tópicos postados, paro para pensar no que está sendo discutido, ainda que não compartilhe as minhas reflexões. (P9)

$\mathrm{O}$ excerto anterior, com as considerações de P9, indica que mesmo aquelas/es participantes que não postam suas reflexões no grupo podem se beneficiar desse recurso virtual para o próprio desenvolvimento profissional. Além disso, P4 e P10 confirmam que participar desse grupo virtual tem nutrido o desejo de continuar sempre estudando, como pode ser notado nos seguintes trechos:

[...] mesmo que minha participação não seja tão ativa como gostaria que fosse, $[. .$.$] ainda assim, me sinto motivada a estudar mais e me$ 
empenhar na minha formação. Até porque, quando entrei no grupo ainda cursava o último ano da faculdade, me sentia ainda mais imatura e inexperiente em relação aos assuntos acadêmicos, e mesmo agora, com o curso concluído, pretendo continuar estudando. (P4)

Além de poder declarar à escola em que trabalho que estou em constante formação, também reconheço que o grupo tem reforçado um antigo sonho, fazer o mestrado. (P10)

Além das contribuições para a própria formação docente, a participação no grupo virtual tem contribuído também para o aprimoramento da prática pedagógica das/os professoras/es.

\section{Contribuições para a prática pedagógica}

Com exceção de um dos participantes que declarou não estar atuando na área de educação no momento, todas/os as/os demais acreditam que a participação no Transição tem trazido benefícios para sua prática docente. P1 afirma que utiliza "especialmente os vídeos que são postados". De modo semelhante, P3 e P10 acreditam que as reflexões que fazem a partir dos materiais compartilhados, ideias e discussões do grupo têm repercutido em suas aulas:

Fico sempre muito atenta ao comportamento e posicionamento dos meus alunos, bem como as leituras permitem que eu abra maiores discussões com eles. (P3)

Com certeza minha prática pedagógica tem modificado. Através de nossas trocas presenciais e virtuais, muitas ideias e materiais vêm sendo compartilhados pelas/os participantes, dessa forma, muitas das minhas aulas são planejadas e inspiradas por vídeos, textos e discussões apresentadas pelas/os colegas. (P10)

Além disso, P4 e P5 ressaltam a contribuição de sua participação no grupo para refletirem sobre sua própria prática, buscando melhor 
compreender e realizar seu trabalho docente com base em perspectivas críticas. Seguem os excertos com suas considerações:

Os links compartilhados e as discussões me fazem refletir sobre meu trabalho em sala de aula, e buscar, cada vez mais, dar sentido aos conteúdos que são trabalhados, especialmente pelo engajamento dos outros participantes do grupo em buscar a reflexão e discussão sobre o trabalho com o ensino-aprendizagem de línguas sob uma perspectiva crítica. (P4)

[...] as trocas de ideias, o material enviado com frequência, as notas de cada participante [...] puderam me motivar a continuar na caminhada por aprender mais sobre o fazer pedagógico na perspectiva crítica. (P5)

Nessa mesma direção, P8 também considera que o grupo tem servido de fonte de ideias e feito com que ela repense alguns valores. Em suas palavras, "tenho refletido e aprendido muito com o grupo. Me nutro de ideias e repenso valores". Cremos que isso ocorra devido à predominância de temas críticos que, como apresentado na seção anterior, têm marcado o conteúdo das mensagens postadas no grupo.

Por outro lado, P9, mesmo considerando que a participação no grupo possivelmente traz repercussões em sua prática docente, uma vez que acredita que tem trazido contribuições para sua formação contínua, não consegue precisar em que medida isso tem ocorrido. A seu ver, isso ocorre devido à sua pouca participação ativa nas interações do grupo. Segue o trecho com as reflexões de P9:

Acredito que tem contribuído para a minha formação contínua, o que, de alguma forma, deve repercutir em minha prática. No entanto, eu não saberia dizer ao certo como isso tem acontecido, já que a minha participação no grupo não tem sido constante como eu achei que seria. (P9) 
Vários fatores têm influenciado a frequência de participação nas interações virtuais do grupo e as/os participantes também teceram considerações a esse respeito.

\section{Autoavaliação sobre a participação no grupo}

Ao fazerem uma autoavaliação sobre a participação nas interações virtuais do grupo, a maioria considera sua participação insatisfatória e diz que gostaria de participar mais ativamente do grupo. No entanto, o fator "falta de tempo" aparece como principal justificativa pela ausência nas interações virtuais. Seguem alguns excertos a esse respeito:

Muito ruim. De pouquíssima qualidade. Quando de fato me ingressei no grupo, fiquei um pouco perdida com a quantidade de envios que ia recebendo ao longo das semanas e, com o tempo escasso para dar as devidas contribuições a tudo, me eximi de responder sempre. [...] Quero ter a oportunidade de fazer diferente este ano. (P5)

Nesse momento, infelizmente, tive uma participação quase nula no sentido de participar mais ativamente das discussões propostas (no início eu estava um pouco mais presente...). Por quê? Bom..., porque minhas atividades aumentaram bastante [segue enumerando suas funções atuais]. (P7)

Como disse, a minha participação no grupo não tem sido constante como eu achei que seria. Na maioria das vezes, não participo por falta de tempo. Ainda assim, reconheço que preciso me organizar melhor e encarar o grupo como mais uma de minhas prioridades profissionais. Se o grupo não for encarado como prioridade, a participação tende a ser insatisfatória. (P9)

No final do último excerto, P9 ressalta a importância de ter o grupo virtual como uma das prioridades profissionais e, desse modo, organizar a administração do (pouco) tempo a fim de ter uma participação, de fato, 
satisfatória. Por outro lado, P4 e P10 apontam fatores de personalidade que também podem influenciar o nível de participação ativa no grupo:

Não sou tão participativa quanto gostaria de ser. Foram poucas as vezes em que comentei algo em alguma discussão. Um pouco pela minha dificuldade em interagir em discussões, tanto nas presenciais como nas virtuais. Mas leio os e-mails que recebo. Leio os comentários dos outros participantes, e até acredito que aprendo ao lê-los. Mas gostaria mesmo de conseguir interagir melhor. (P4)

Procuro participar de todos os encontros presenciais, porém acredito que eu poderia contribuir mais nas discussões virtuais. Muitas vezes deixo de opinar, simplesmente gosto mais de ouvir do que de falar. (P10)

Desse modo, é possível inferir, a partir das colocações dessas/es respondentes do questionário, algumas das razões que inibem a participação mais ativa por grande parte das/os participantes do Transição. Além dos possíveis motivos que prejudicam a frequência de participação em comunidades virtuais elencados por Calvo et al. (2013), citados na seção anterior, podemos acrescentar a dificuldade em administrar as múltiplas temporalidades profissionais, sociais e pessoais (KENSKI, 2013) e a diversidade de estilos de aprendizagem (aprende-se no silêncio também). Como argumenta Perin (2013, p. 82),

... é na harmonização de diferentes modos de adesão às diversas CPs [comunidades de prática - como pode ser entendido o grupo de estudo virtual em foco] que se dá o processo de formação de parte da identidade dos[as] integrantes, assim como a participação passa a ter sentido, à medida que cria o senso de pertencimento. É ainda necessário tratar o silêncio como forma de participação, já que ele pode ser causado por limitações do trabalho.

Por sua vez, outras duas participantes avaliaram sua participação no grupo como muito ativa e satisfatória, respectivamente. A participante que 
considera que participa muito o faz porque gosta das discussões e se sente no compromisso de participar. A outra participante considera sua participação satisfatória porque sempre que possível contribui com sugestões de leituras ou materiais que possam fomentar discussões e ajudar nas aulas das/os demais colegas.

Percebe-se, então, que a autoavaliação que fizeram sobre a participação nas interações virtuais do grupo corroboram a análise feita na seção anterior, que indicou um número mais elevado de participantes silenciosas/os do que de ativas/os no grupo virtual. Porém, aponta também que a ausência de participações mais ativas não indica que as/os participantes não estejam se beneficiando desse recurso virtual para o próprio crescimento profissional.

\section{Vantagens e desvantagens de participar de um grupo de estudos virtual}

Para concluir, as/os participantes elencaram o que elas/eles consideram como vantagens e desvantagens de participar de um grupo de estudos virtual. Como uma das vantagens, elas/ eles apontam esse recurso virtual como meio de estar em contato frequente com pessoas de diferentes locais e contextos educacionais, mas com interesses em comum, e a possibilidade de aprendizagem colaborativa. Seguem alguns excertos:

... é uma forma de estar em interação com pessoas de diferentes contextos educacionais e cidades, já que encontros presenciais são cada vez mais difíceis e raros. (P1)

Maior possibilidade de contato frequente; possibilidade de "estar" com profissionais e estudantes de diferentes localidades. (P2)

... a promoção de discussões pautadas no que é interesse comum do grupo; [...] trocas de experiências e aprendizagem colaborativa. (P5)

Além disso, consideram como grande vantagem desse recurso virtual a flexibilidade de tempo que ele proporciona, uma vez que podem organizar o acesso às mensagens compartilhadas quando lhes for conveniente e possível, sem uma agenda pré-estabelecida. Seguem algumas considerações a esse respeito: 
Podemos nos comunicar a qualquer hora, temos tempo para ler, refletir e contribuir. Ao vermos algo interessante temos a possibilidade de encaminhar imediatamente para os colegas. (P3)

Vejo como uma vantagem o fato de você poder ler uma postagem, ou um link compartilhado, e ter o tempo que julgar necessário para refletir sobre o que viu e responder quando achar que deve ou tem condições de dizer algo que contribua com o que é discutido. A participação no grupo virtual acaba sendo mais flexível. (P4)

... não fosse o grupo virtual, nesse momento, eu não poderia estar a par das discussões que estão sendo realizadas... (P7)

A maior vantagem é que podemos organizar a nossa participação em casa, sem a pressão de um encontro presencial, por exemplo, no qual os textos precisam ser lidos previamente e a discussão possui datas e horários fixos para acontecer. (P9)

Vivemos um momento único, não temos tempo pra nada. Temos que realizar inúmeras coisas em pouco tempo, por isso ganhamos tempo participando de um grupo de estudos virtual. (P10)

As colocações expressas nesses últimos excertos estão em consonância com o argumento de Kenski (2013, p. 126) de que "o tempo dos ambientes virtuais é diverso e infinito". Por outro lado, essa flexibilidade proporcionada pelo ambiente virtual pode levar algumas/uns participantes a conceberem esse espaço como secundário em suas prioridades, como argumenta P9:

Por outro lado, devido à comodidade propiciada pela participação online, as/os participantes podem acabar deixando essa atividade para segundo plano ou realizando-a de forma insatisfatória acredito que esse seja o meu caso. (P9)

Outra desvantagem desse recurso virtual, apontada por P1, é que as reflexões, quando expressas, tendem a ser breves e menos elaboradas, pois 
escrever, por vezes, exige mais tempo e elaboração das ideias. Segue o trecho com as considerações de P1:

A desvantagem é que as interações tendem a ser breves. Pode ser que gerem muita reflexão, mas essas reflexões não são expressas ou não são bem elaboradas como seriam se os encontros fossem presenciais, e a razão disso, novamente, é a falta de tempo, já que escrever requer mais elaboração do que falar. (P1)

Ademais, P2, P3, P7, P8 e P10 apontam como desvantagem desse recurso virtual a ausência de contato face a face entre as/os participantes, o que P10 acredita poder levar algumas/uns participantes a se eximirem da participação mais ativa no grupo:

Falta do contato direto com as pessoas. (P2)

Pra mim, a única desvantagem é a distância... Adoraria estar presente! (P3)

... não ver as pessoas cara a cara... (P7)

A desvantagem é não poder ver meus colegas com mais frequência. (P8)

... a distância proporcionada pelo recurso e os poucos encontros presenciais levam algumas/alguns participantes a se acomodarem. (P10)

A respeito da pouca participação nas interações virtuais, P5 aponta como desvantagem o constrangimento que sente quando não expressa suas reflexões no grupo:

... constrangimento - quando há um debate e eu não podia postar minha contribuição, ficava muito envergonhada. (P5) 
Possivelmente, P5 aponta essa desvantagem devido ao sentimento de interdependência que, em geral, é fomentado em uma comunidade (LOPES, 2011), seja ela virtual ou não. Como coloca Lopes (2011, p. 152), com base em Cutler (1995), "a presença social no ciberespaço assume uma sensibilização recíproca, individual e coletiva, criando um senso de interação que é essencial àqueles[as] que estão lá". Sendo assim, o fato de não poder contribuir ativamente no grupo, ou seja, responder às mensagens postadas, gera um sentimento de constrangimento em P5 e que, provavelmente, aflige outras/os participantes do grupo.

Apresentados alguns olhares de dentro do grupo Transição, que ajudam a visibilizar os sentidos construídos para esse recurso virtual de formação, seguimos com as últimas considerações deste estudo.

\section{Considerações Finais}

A análise do conteúdo das mensagens de iniciação enviadas pelo grupo de estudos virtual Transição e das considerações de algumas/uns participantes, geradas a partir de um questionário semiaberto, indicam que esse recurso da Web 2.0 pode, de fato, trazer contribuições para a formação de professoras/es de LE/LA. Algumas das contribuições apontadas pela análise são: possibilidade de formação contínua e aprendizagem colaborativa com profissionais de diferentes contextos educacionais e regiões do país, discussão de temáticas e compartilhamento de materiais de interesse comum de modo flexível e aprimoramento da própria prática pedagógica.

Por outro lado, a análise aponta também algumas limitações desse recurso virtual, como: baixo percentual de participantes ativas/os, demasiada demanda de tempo para acessar o conteúdo das mensagens e responder a elas, comodidade proporcionada pelo recurso que pode levar algumas/uns participantes a não ter o grupo como prioridade profissional; impossibilidade de interação face a face (o recurso não disponibiliza vídeo conferência, por exemplo). Acrescentamos, ainda, como uma limitação desse recurso da Web 2.0 (especificamente, Grupos do Google) a impossibilidade de organizar em arquivos temáticos dentro do próprio espaço virtual o material compartilhado pelo grupo.

Prensky (2012) prevê que o trabalho em comunidades virtuais será uma das habilidades requeridas da próxima geração e, nesse sentido, temos 
muito ainda a aprender, especialmente sobre colaboração efetiva em ambientes virtuais, a fim de que tenhamos condições de contribuir para o aprimoramento dessa habilidade por nossas/os alunas/os. Um grande desafio é tornar as conversas mais complexas e fazer com que a função de autora/autor se sobreponha à função de leitora/leitor (MOTA; SCOTT, 2014). Outro desafio a ser superado em nosso país é a real democratização do acesso aos recursos da Web 2.0 e das demais gerações da internet que estão por vir. Em meados da segunda década do século XXI, quantas/os professoras/es de LE/LA em nosso país seguem seu trabalho solitário, sem ter a oportunidade de compartilhar suas ideias e questionamentos com outros pares, nem mesmo de modo virtual?

Este estudo apontou um caminho, dentre os vários potencializados pela Web 2.0, para a formação continuada docente. Resta-nos, agora, buscar maneiras de otimizá-lo, problematizando suas limitações e, ao mesmo tempo, torná-lo mais acessível a outras/os professoras/es de LE/LA.

\section{Referências}

ANDRELO, R.; NAKASHIMA, R. H. R. A formação de professores e o uso pedagógico da Web 2.0: a visão de estudantes de licenciatura. Educação Unisinos, v. 16, n. 12, p. 125-134, maio/ago., 2012.

BOHN, V. C. R. Comunidades de prática na formação docente: aprendendo a usar ferramentas da Web 2.0. 2010. Dissertação (Mestrado em Letras: Estudos Linguísticos) - Universidade Federal de Minas Gerais, Belo Horizonte.

CALVO, L. C. S.; FREITAS, M. A. Uma análise das mensagens eletrônicas 2010-2011 do grupo de formadores de professores de Língua Inglesa do Paraná. In: ENFOPLI, 8., 2011, Maringá. Anais... Maringá: UEM, 2011.

CALVO, L. C. S. et al. A comunidade de prática ENFOPLI/PR em interação virtual: a natureza de suas mensagens eletrônicas. In: CALVO, L. C. S. et al. (Orgs.). Reflexões sobre ensino de línguas e formação de professores no Brasil. Campinas: Pontes, 2013. p. 311-348. 
CUTLER, R. Distributed presence and community in cyberspace.

Interpersonal Computing and Technology: An electronic Journal for the 21st Century, v. 3, n. 2, p. 12-32, Jan. 1995.

DENZIN, N. K.; LINCOLN, Y. S. A disciplina e a prática da pesquisa qualitativa. In: DENZIN, N. K.; LINCOLN, Y. S. (Orgs.). O planejamento da pesquisa qualitativa: teorias e abordagens. Porto Alegre: Artmed, 2006.

KENSKI, V. M. Tecnologias e tempo docente. Campinas: Papirus, 2013.

FREITAS, G. M. de O. Ferramentas da Web 2.0 na formação de professores para o uso das tecnologias da informação e comunicação na sala de aula. Salvador, p. 1-20, abr. 2012. Disponível em < http://bit.do/ bFJMD>. Acesso em: 5 fev. 2014.

LOPES, M. C. L. P. Comunidade virtual no ensino-aprendizagem de línguas: interação, diálogo e colaboração. In: MACIEL, R. F.; ARAÚJO, V. de A. (Orgs.). Formação de professores de línguas: ampliando perspectivas. Jundiaí: Paco, 2011. p. 141-154.

MARZARI; G. Q.; LEFFA, V. J. O letramento digital no processo de formação de professores de línguas. Tear. Revista de Educação Ciência e Tecnologia, Canoas, v. 2, n. 2, p. 1-18, 2013.

MOTA, R.; SCOT'T, D. Educando para inovação e aprendizagem independente. Rio de Janeiro: Elsevier, 2014.

NICOLAIDES, C. S.; TILIO, R. C. Políticas de ensino e aprendizagem de línguas adicionais no contexto brasileiro: o caminho trilhado pela ALAB. In: NICOLAIDES, C. S. et al. (Orgs.). Política e políticas linguisticas. Campinas: Pontes, 2013. p. 285-305.

NIELSEN, J. Participation inequality: encouraging more users to contribute. Oct. 9, 2006. Disponível em: <http://bit.do/bFJMF>. Acesso em: 5 fev. 2014.

OLIVEIRA, E. C. de. Navegar é preciso! - o uso de recursos tecnológicos para um ensino-aprendizagem significativo de línguas estrangeiras. In: PEREIRA, A. L.; GOT'THEIM, L. Materiais didáticos para o 
ensino de língua estrangeira: processos de criação e contextos de uso. Campinas: Mercado de Letras, 2013. p. 185-214.

PERIN, J. O. R. ENFOPLI: emergência e construção de uma comunidade de prática de formadores de professores de inglês. 2009. Tese (Doutorado em Estudos da Linguagem) - Universidade Estadual de Londrina, Londrina.

PERIN, J. O. R. A participação em 'comunidades de prática' como possibilidade de desenvolvimento profissional para formadores de professores de línguas. In: TONELLI, J. R. A.; CHAGURI, J. de P. Espaço para reflexão sobre ensino de línguas. Maringá: EDUEM, 2014. p. 67-84.

PESSOA, R. R. A critical approach to the teaching of English: pedagogical and identity engagement. Revista Brasileira de Linguistica Aplicada, Belo Horizonte, v. 14, n. 2, p. 353-372, 2014.

PRENSKY, M. Teaching the right stuff - Not yesterday's stuff or today's but tomorrow's!. 2012. Disponível em: <http://bit.do/bFJMJ>. Acesso em: 10 dez. 2013.

SALLOWICZ, M. Acesso à internet no Brasil cresce, mas 53\% da população ainda não usa a rede. Folha de S. Paulo, São Paulo, 16 maio 2013. Disponível em: <http://bit.do/bFJMA>. Acesso em: 25 jan. 2014.

TARDIF, M.; LESSARD, M. C. O trabalho docente: elementos para uma teoria da docência como profissão de interações humanas. Petrópolis: Vozes, 2008.

URZÊEA-FREITAS, M. T. Educando para transgredir: reflexões sobre o ensino crítico de línguas estrangeiras/inglês. Trabalhos em Linguística Aplicad, Campinas, v. 51, p. 77-97, 2012.

Recebido em: $11 / 12 / 2014$ Aceito: $29 / 04 / 2015$ 